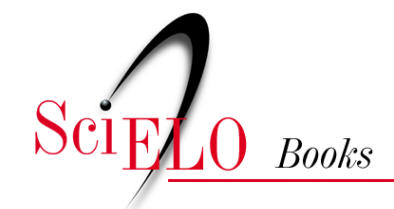

EDUFU

\title{
Cenografia e indumentária na arte-educação
}

\author{
Gilson Motta
}

\section{SciELO Books / SciELO Livros / SciELO Libros}

MOTTA, G. Cenografia e indumentária na arte-educação. In: FLORENTINO, A., and TELLES, N., eds. Cartografias do ensino do teatro [online]. Uberlândia: EDUFU, 2008, pp. 103-112. ISBN 97885-7078-518-3. https://doi.org/10.7476/9788570785183.0011.

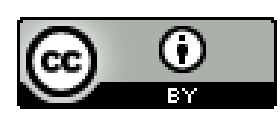

All the contents of this work, except where otherwise noted, is licensed under a Creative Commons Attribution 4.0 International license.

Todo o conteúdo deste trabalho, exceto quando houver ressalva, é publicado sob a licença Creative Commons Atribição 4.0.

Todo el contenido de esta obra, excepto donde se indique lo contrario, está bajo licencia de la licencia $\underline{\text { Creative Commons }}$ $\underline{\text { Reconocimento 4.0. }}$. 


\section{Cenografia e indumentária na Arte-Educação}

Gilson Motta

O tema deste ensaio - a Cenografia e a indumentária na Arte-Educação - foi sugerido pelos organizadores deste periódico visando desenvolver o debate em torno da reforma curricular no âmbito das licenciaturas. Neste texto, tento contribuir para este debate fazendo uma reflexão sobre os fundamentos destas atividades, pensadas aqui de modo indiferenciado. O elemento que se antepõe de modo não explícito é a própria idéia do teatro, isto é, as características básicas do fenômeno teatral enquanto elemento configurador da plasticidade. Pensar no sentido de cenografia e indumentária no contexto da formação do arte-educador implica, antes, um pensar crítico sobre o sistema de produção teatral. Esta reflexão pode conduzir, de um lado, à ratificação dos procedimentos criativos herdados pela tradição, mas, por outro, ela pode apontar para metodologias diferenciadas voltadas para a uma autêntica formação estética do aluno. Num primeiro momento, farei uma caracterização geral destas disciplinas, valorizando sua natureza teórico-prática; num segundo, situarei estas disciplinas no âmbito do ensino destacando aspectos que considero relevantes para a formação do arte-educador.

\section{Cenografia e indumentária como artes visuais}

Cenografia, indumentária, iluminação e maquiagem são chamados de elementos visuais do espetáculo. Em sua interação e integração no espetáculo, eles transmitem mensagens visuais, construindo um efeito visual. Embora os atores também possam ser vistos como elementos transmissores de mensagens visuais de acordo com sua posição e deslocamento no espaço, só os elementos acima contêm uma linguagem visual, isto é, um conjunto de signos visuais articuladores de um sentido.

Codificada pela psicologia da Gestalt e pela Bauhaus, a linguagem visual manifesta sua presença nas obras, sobre a plasticidade do teatro, produzidas na Europa e nos Estados Unidos a partir da década de 1950. Assim, a modernidade no teatro é construída com os estudos sobre a linguagem visual e com as experiências formais desenvolvidas entre o final do século XIX e as vanguardas artísticas. Por um lado, as experiências formais geram novas relações entre os elementos da linguagem visual; por outro, tais elementos tornam legíveis os estilos e formas teatrais. Este fato tornou possível - em especial nos textos norte-americanos - a presença de classifi- 
cações de cenários, por tipos ou estilos ${ }^{1}$. Embora esta classificação não tenha mais efeito na cena contemporânea, ela é importante por permitir realizar na esfera da composição visual do teatro aquilo que Donis A. Dondis chama de "alfabetização visual" ": o entendimento das mensagens visuais presentes em cada estilo ou forma teatral. Este entendimento da cultura visual é o ponto de partida para o desenvolvimento do gesto criativo do aluno.

Em suma, enquanto pertencentes ao universo da visualidade e da plasticidade, os elementos visuais do espetáculo são regidos pela linguagem visual, sendo idênticos em seus fundamentos. Daí a interdependência dos mesmos, quando da criação de um espetáculo teatral. Portanto, um primeiro aspecto a ser considerado na Indumentária e na Cenografia é que ambas são atividades artísticas cuja criação e recepção funda-se na linguagem visual.

\section{O invisível na cenografia e na indumentária}

No capítulo anterior, indiquei o vínculo entre a linguagem visual e os elementos visuais do espetáculo. Subentende-se que, numa relação de ensino-aprendizagem, é essencial caracterizar cenografia e indumentária como artes visuais. Apresentarei agora a relação da cenografia e da indumentária com um elemento não visual: a palavra.

O sistema de produção teatral vigente sustenta-se, por via de regra, na relação diretor-autor. Nesta relação, o diretor propõe uma interpretação do texto, determinando um conceito ou temática básica de encenação, que informará as demais atividades criadoras. O texto constitui-se, portanto, como um elemento de origem, que contém uma antecedência e uma autonomia em relação à cena. E, embora, na atualidade, o texto já não ocupe um lugar privilegiado na estética teatral, ele continua exercendo a função de elemento de referência, articulador do sentido do espetáculo. Enfim, a criação visual no teatro é informada pelo drama.

A palavra ou texto pertence ao elemento temporal, sonoro e, portanto, ao invisível. Em "A exibição das palavras", Denis Guénoun afirma que o fenômeno teatral se constrói a partir da tentativa de tornar visíveis as palavras. A teatralidade relaciona-se à visibilidade. "A teatralidade não está no texto. Ela é a vinda do texto ao olhar. Ela é este processo pelo qual as palavras saem de si mesmas para produzir o visível. A teatralidade é o próprio pôr/em/cena" ${ }^{3}$. A encenação seria a arte da passagem do elemento lingüístico ao visual e vice-versa.

Estas observações são importantes para se pensar a dimensão interpretativa da cenografia e da indumentária teatrais, pois ambas transformam o que é conceito em imagem, de modo a configurar a linguagem do espetáculo. Esta dupla interpretação envolve o conhecimento das artes visuais, mas, sobretudo, um conhecimento da dramaturgia, mais precisamente, da teatralidade do drama, de sua visualidade virtual.

\footnotetext{
${ }_{1}$ Esta classificação apresenta-se em várias obras. Ver, por exemplo: SELDEN, Samuel; SELLMAN, Hunton. Stage scenery and lighting: a handbook for non-professionals. New York: Appleton-Centry-Crofts, [19--]; PARKER, Oren; SMITH, Harvey K. Scene design and stage lighting, New York: Holt, Rinehard and Winston, 1966; NELMS, Hennig. Scene design: a guide to the stage. New York: Dover Publicatons, 1975. 96 p.

${ }^{2}$ Cf. DONDIS, Donis A. Sintaxe da linguagem visual. São Paulo: M. Fontes, 2000. 236 p.

${ }^{3}$ GUÉNOUN, Denis. A exibição das palavras: uma idéia (política) do teatro. Rio de Janeiro: Teatro do Pequeno Gesto, 2003. p. 55.
} 
Ora, por ser uma arte integrada, o teatro possui uma linguagem extremamente complexa. Além de fundarem-se na linguagem visual, cenografia e indumentária são parte de um sistema semiológico amplo que envolve a interação das artes do espaço e das artes do tempo. Esta interação atribui ao signo teatral uma intensa mobilidade: a escrita cênica é uma configuração de sentido originada do dinamismo entre o ator, os elementos visuais e os elementos sonoros do espetáculo. Assim, no teatro, as relações formais possuem um campo de abrangência muito extenso, já que os elementos móveis e temporais estão aí contidos.

Enfim, cenografia e indumentária são artes visuais que conservam uma relação com o invisível: o teatro comporta uma visualidade diferenciada, porquanto informada por elementos dinâmicos visíveis (ator e luz) e invisíveis (palavra, música). Entender a articulação entre o visível e o invisivel é essencial para a criação visual no teatro. Por conseguinte, no âmbito do ensino do teatro, é fundamental valorizar este aspecto.

\section{Apresentação de um problema: formação técnica e formação estética}

Cenografia e indumentária são atividades que envolvem conteúdos teóricos e práticos. Os capítulos anteriores apontaram para duas dimensões nas atividades dos criadores visuais do espetáculo. Uma relaciona-se à exterioridade num sentido amplo, pois os próprios instrumentos e aparelhos do palco, por exemplo, são apreendidos como elementos de construção da plasticidade do espetáculo. A outra diz respeito a uma dimensão introspectiva, a uma constante ação que o artista exerce sobre si mesmo. Juntas, as duas determinam o estilo, enquanto escrita absolutamente pessoal. Portanto, estas duas dimensões são inseparáveis, como nota José Dias:

O êxito do cenógrafo não depende apenas de um bom texto, de uma boa proposta da direção ou de uma inspiração genial, mas de todos esses fatores. Se os primeiros, o texto e a direção, como fatores externos, dependem às vezes de sorte, de oportunidade, os fatores internos, a inspiração e a capacidade do artista, dependem do talento e da formação profissional; da chamada alma de artista, bem como de paciência e calma para desenvolvê-la ${ }^{4}$.

Uma dimensão é estética no sentido de um trabalho com as formas (a composição, o significado do objeto artístico). Outra é estética por se referir ao processo dinâmico da sensibilidade. A presença simultânea destes fatores externos e internos é um fator problemático na formação do arte-educador, pois os elementos técnicos e expressivos nem sempre podem ser contemplados nos cursos de formação.

Cenógrafo e figurinista são profissionais que devem dominar técnicas de projeção gráfica, técnicas de construção, devem saber dialogar com profissionais diversos, devem ter o conhecimento de diversos materiais expressivos. O oficio do figurinista e do cenógrafo envolve uma grande gama de conhecimentos (históricos, teóricos, artísticos, técnicos, culturais), mas é somente na prática artística que a razão de ser destes conhecimentos é posta à prova. O fundamental nestes dois ofícios é, portanto, o domínio técnico, um saber instrumental que possa vir a fornecer soluções para problemas tópicos. Se

\footnotetext{
${ }^{4}$ DIAS, José. A importância da cenografia. O Percevejo, Rio de Janeiro, ano 7, n. 7, p. 29, 1999.
} 
este fato dá a tônica do trabalho do criador visual no teatro, ocorre então que ele entra em conflito com o próprio oficio do arte-educador, já que o aluno de licenciatura possui uma abordagem mais generalizada dos aspectos da arte teatral. Ele não é um especialista do fazer teatral. Contudo, em seu ofício, o arte-educador deve estar apto a responder às questões gerais relativas a áreas como direção, interpretação, iluminação, figurinos, cenografia. Esta solicitação de respostas imediatas ocorre, por exemplo, quando são feitas montagens teatrais com alunos. Ora, a especificidade da formação do arte-educador está menos na capacidade de propor soluções técnicas do que na capacidade de formar sensibilidades e potencialidades. Cenografia e indumentária devem ser apenas meios para que o arte-educador possa vir a desenvolver nos alunos outras qualidades de sensibilidade, outras formas de inteligência e outros comportamentos criativos.

Os aspectos destacados aqui - a linguagem visual, a interpretação, a fusão da estética e da técnica visam determinar as características essenciais da cenografia e da indumentária. É a partir destes traços essenciais que podemos pensar no modo como elas devem ser abordadas no contexto do ensino.

\section{Cenografia e indumentária na formação e na prática profissional do arte-educador}

A formação do cenógrafo e do figurinista envolve conhecimentos teóricos e de conhecimentos técnicos. A matriz curricular do curso de Cenografia e de Indumentária da Universidade Federal do Rio de Janeiro - UNIRIO, por exemplo, consta de uma extensa carga horária voltada para o desenvolvimento da expressão plástica (desenho, geometria, perspectiva, modelo vivo, perspectiva e sombra, entre outros) e para os conhecimentos técnicos (corte e montagem, modelagem, adereços, entre outros).

Quando oferecidas a outros cursos - direção, interpretação, teoria, licenciatura - Cenografia e Indumentária têm seu enfoque transformado, já que elas tornam-se mais condensadas em função da reduzida carga horária, a qual, na maioria das escolas de teatro (UNIRIO, UFMG, ECA-USP, UFOP, UFRGS, UDESC, entre outras) tende a variar entre 60 e 120 horas. De minha parte, quando ministro estas disciplinas para cursos como Direção Teatral, Interpretação e Licenciatura, evito valorizar os aspectos relativos à cenotécnica, preferindo destacar os elementos da construção estética do espetáculo: relação diretor-cenógrafo ou figurinista, semiologia, linguagem visual do espetáculo, tipologia do espaço cênico, luz-cena, ator-espaço, etc. Na Licenciatura, em particular, há ainda uma outra mudança de enfoque, pois o fundamental aqui é mostrar como o professor-orientador pode usar dos elementos visuais do teatro para poder formar a sensibilidade do aluno. Neste sentido, estão em jogo questões relativas à percepção do espaço, ao entendimento dos valores e qualidades espaciais, à apreensão dos elementos visuais que tornam expressivo o espaço, entre outros.

Contudo, esta mudança tem sido mais difícil e problemática devido justamente às referidas solicitações técnicas, as quais trazem muitos problemas para o professor orientador. Dentre os problemas que considero mais freqüentes e mais interessantes, podemos listar os seguintes: 
1) O professor-orientador tem poucos recursos de expressão gráfica ou plástica, mas precisa elaborar um cenário para cenas criadas pelos alunos.

2) O professor-orientador elaborou junto com seus alunos os figurinos e cenários para um espetáculo, mas não sabe como elaborar os planos de custo para a execução da montagem.

3) A instituição e/ou comunidade dispõe de um espaço para criar uma espécie de centro cultural, onde haverá um pequeno teatro e solicita ao professor de teatro a elaboração de um projeto para o espaço.

4) Uma montagem teatral está sendo realizada com trajes recuperados, mas a diversidade das peças dificulta o estabelecimento da unidade do figurino.

Esta lista foi construída a partir de situações concretas vivenciadas ou por mim ou por meus alunos, cada item diz respeito a um aspecto específico do fazer teatral. As situações 1 e 4 estão relacionadas à linguagem do espetáculo teatral, envolvendo questões de ordem técnica e estética. A situação 2 relaciona-se à produção e à técnica. Já a situação 3 diz respeito à arquitetura cênica. Aquilo que todas estas situações têm em comum é o fato de elas exigirem a presença de um profissional especializado, já que não podem ser resolvidas por um professor de teatro. Isto é, o licenciado em teatro não tem a menor obrigação de dominar estes conteúdos. E, o fato dele desconhecer tais procedimentos não constitui uma falha em sua formação.

Mas é justamente neste ponto que tem início o problema: por força de sua formação específica, o professor de teatro desconhece os aspectos técnicos envolvidos na indumentária e na cenografia, mas seu ofício lhe exige constantemente a necessidade de propor soluções técnicas para problemas concretos. Considerando que, nem sempre, ou quase nunca, a instituição tem condições de contratar profissionais especializados para executar tais serviços, devemos nos perguntar se existe uma maneira de atenuar este problema, durante a formação do arte-educador.

\section{Desenvolvimento da expressão gráfica: o desenho}

Como vimos, quando transpostos para o universo da Licenciatura, cenografia e indumentária sofrem uma condensação de seu conteúdo. Assim, num curso de 120 horas, divididas em dois semestres, o aluno lida com uma multiplicidade de informações complexas que abrangem todos os elementos necessários para a elaboração de um projeto cenográfico para um texto (teoria, história, expressão, técnica). Os conteúdos teóricos são de mais fácil manipulação, visto dependerem exclusivamente da análise das obras; já os conteúdos de mais difícil transmissão são os que envolvem elementos técnicos e expressivos, em especial, o desenho. Em sua grande maioria, os professores de teatro possuem mais conhecimentos nas áreas de interpretação e de direção teatral, pois, em geral, são atores que manifestam interesse pelo ensino. Raramente encontramos cenógrafos ou figurinistas que optaram também pela licenciatura. 
As experiências de sala de aula têm me mostrado que, em sua grande maioria, os alunos têm grandes dificuldades de realizar um projeto cenográfico, pois isto implica vários conhecimentos técnicos fundados na expressão gráfica e plástica. Ao serem solicitados a elaborar projetos de cenografia para um texto teatral, eles tendem a resistir à dimensão técnica (o que envolveria croquis, perspectivas, plantas baixas, cortes, planta de construção, maquete) e aos elementos práticos, como elaboração de plano de custos, orçamentos, quantitativo de materiais. Se, por um lado, esta resistência não afeta o objetivo central da disciplina, por outro, ocorria que a maior parte dos alunos nunca sabia como uma determinada idéia seria executada: a técnica, enquanto meio para se chegar a um fim, permanecia alijada do processo. Um projeto cenográfico se limitava a uma boa idéia (entenda-se, um bom discurso) e a alguns desenhos mal feitos. Em suma, a cenografia era traída em sua natureza. De minha parte, eu traía os ensinamentos do professor Anísio Medeiros, que repudiava a idéia de uma "cenografia falada". O desenho se fazia, portanto, necessário.

Ora, assim como qualquer forma de expressão artística, a arte de desenhar implica a existência de uma capacidade prévia e de um tempo de exercício para seu desenvolvimento. Mas, num curso de 30 aulas, são reservadas 5 aulas - no máximo - para o desenho, o que considero absolutamente improdutivo. Assim, a possibilidade de desenvolver o potencial expressivo do aluno é tolhida em função do tempo.

Deste modo, um procedimento acadêmico que considero importante é propiciar ao aluno de Licenciatura em Teatro o contato com aulas de desenho: livre, artístico, técnico, de moda. Estas aulas devem se configurar como disciplinas optativas ou como oficinas, sendo oferecidas no mesmo período ou no período anterior ao das disciplinas em questão. O objetivo destas aulas não deve ser o de gerar desenhistas: mais importante é fazer o aluno entender o desenho como uma ferramenta básica para ele expor suas idéias. Igualmente importante é preparar o olhar do aluno para os tratamentos gráficos específicos, isto é, fazer o aluno compreender a representação de tecidos, de caimentos, de volumes, entre outros. Com isso, ele poderá manter um diálogo mais fluido com os profissionais que executam seu projeto, evitando erros de interpretação. O que se nota assim é que o conhecimento básico do desenho pode contribuir para que o futuro professor de teatro possa resolver alguns dos problemas listados acima: a visão do conjunto de personagens possibilita a correção da falta de unidade; o desenho permite ainda uma primeira projeção ou materialização das idéias, possibilita ainda a projeção do espaço.

\section{Laboratórios de criação: dos materiais expressivos à cena}

Iniciemos com as palavras de Gianni Ratto:

O material de desenho é importante para poder traduzir em linha, cores ou sombras nossas idéias, mas acho que se pensarmos em materiais nossa tarefa ficará potencializada: quer dizer, deixar que a matéria aceite ou não ser utilizada por nossa imaginação ${ }^{5}$.

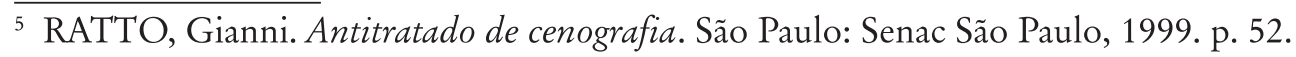


O tempo reduzido conduz também a uma desvalorização de um elemento específico das disciplinas de Indumentária e de Cenografia: o conhecimento das potencialidades expressivas dos materiais e, por conseguinte, com as técnicas de confecção e montagem. Na matriz curricular do curso de Licenciatura em Artes Cênicas da Universidade Federal de Ouro Preto há uma disciplina chamada "Materiais expressivos", cujo objetivo é possibilitar aos alunos um contato com os diversos materiais utilizados na criação teatral (madeiras, papéis, tecidos, metais, plásticos, etc.), e com as diversas técnicas de transformação destes materiais. Assim, de acordo com a abordagem do professor, a disciplina pode conter elementos de cenotécnica, de adereços, de figurinos e de confecção em geral.

Feito a partir de visitas a espaços de produção (oficinas de bonecos, cenotécnicas, carpintarias, oficinas de costura, etc.) ou a espaços culturais (teatros, museus, edifícios históricos, festas, manifestações folclóricas, entre outros), este contato permite ao aluno dois tipos de aprendizado. Num nível mais imediato, eles tomam conhecimento das técnicas e soluções plásticas empregadas por artistas e técnicos teatrais, ou seja, eles assimilam procedimentos para empregá-los em outro contexto. No caso da indumentária, uma visita ao guarda-roupa do Centro Técnico do Palácio das Artes, por exemplo, possibilita uma assimilação de soluções de acabamento do traje, tratamento das peças, materiais alternativos usados para a confecção do traje, entre outros. Na cenografia, uma visita a este mesmo espaço permite assimilar as diversas possibilidades formais de um único material, as diferentes técnicas de tratamento dos materiais, assim como os "macetes" dos cenotécnicos. Este contato com os materiais e com os profissionais pode auxiliar o aluno a elaborar planos de custo, orçamentos e especificar quantidades de materiais.

Num nível mais amplo, visitas desta natureza estabelecem um contato com o fazer coletivo. Os grandes espetáculos envolvem imenso número de artistas, artesãos e técnicos e, conseqüentemente, uma diversidade de ofícios e uma variedade de modos de fazer. Os alunos são lançados no ambiente do fazer teatral, numa cultura viva, onde teoria e prática não se distinguem, onde o conhecimento é transmitido ainda sob outros moldes, tais como, a relação mestre e aprendiz. Assim, a observação dos materiais conduz aos produtores e ao sistema de produção e, por fim, ao fenômeno cultural cuja natureza é essencialmente política. Em suma, ao se pensar nos materiais expressivos, pensa-se também nas práticas culturais, num conjunto de procedimentos técnicos e nos agentes da criação.

Concluindo, no que se refere à formação do arte-educador, ao me referir aos materiais e às oficinas de criação, aponto para a necessidade de as escolas de teatro possuírem laboratórios onde o aluno possa fazer experiências cênicas sistemáticas com os diversos materiais, explorando os elementos da linguagem visual. Laboratórios não somente de criação plástica, mas de experimentação cênica, que permitam o desenvolvimento de pesquisas com o ator, o espaço, a luz, o objeto, o traje. Por outro lado, tendo em vista o aspecto social e político, convém destacar que o professor de teatro ou o aluno de licenciatura encontra nestas práticas culturais um grande material de exploração para o desenvolvimento de uma série de atividades, as quais envolverão outros conteúdos didáticos e outras disciplinas. 


\section{Metodologia da criação visual no teatro: entre o mesmo e o diferente}

Vimos que a criação visual no teatro funda-se numa articulação entre os elementos visuais e os não visuais, na interpretação do conceito de encenação e do texto dramático, e, por fim, na capacidade técnica. Acredito que, para atender ao mercado teatral, a metodologia presente nas obras didáticas ou técnicas sobre cenografia e indumentária são suficientes.

O modo pelo qual um cenógrafo ou um figurinista chega a uma idéia envolve vários fatores subjetivos, de forma que tentar estabelecer um "método" comum a todos é um contra-senso, já que, por sua natureza, este processo resiste à transmissão ou à reprodução. Contudo o sistema de produção teatral determina um modo de criação semelhante para todos os artistas. Por conseguinte, apesar da dimensão subjetiva, é possível se identificar fatores gerais, sujeitos a um registro objetivo, logo, passíveis de transmissão. São estes “fatores gerais" que aparecem nas obras didáticas ou técnicas. Para orientar e estimular o processo criativo, algumas obras apresentam questões que o figurinista ou cenógrafo deve colocar na ocasião em que elaboram projetos. Qual o sentido do texto (análise dramatúrgica)? Qual o conceito da encenação? Que tipo de espaço cênico é mais apropriado para a encenação? Qual o estilo da representação? Que abordagem de figurinos deve ser adotada (realistas, estilizados, abstratos)? Quais as necessidades do ator em relação aos figurinos? Qual a dinâmica do movimento dos atores? Que materiais iconográficos serão necessários para a definição formal? Que cores e formas podem traduzir melhor uma idéia?

Estas perguntas constituem um estímulo válido para o aluno apreender o modo como o drama informa a cenografia e a indumentária. Mas, deve-se entender que, o processo de criação visual no teatro envolve uma experimentação contínua. Isto é, estas perguntas não são respondidas conceitualmente, mas sim plasticamente. A idéia gera formas que, por sua vez, esclarecem a idéia dando-lhe materialidade. É neste ponto que a confecção de maquetes tem se afirmado como um elemento fundamental do estudo e da criação: nela, os materiais são potencializados, de modo a superar as próprias dificuldades de expressão gráfica. Na maquete, as massas, as cores e os volumes são postos em cena, são visualizados concretamente, possibilitando uma antevisão do fenômeno cênico.

Aqui, mais uma vez, sugere-se que as escolas de teatro possuam oficinas necessárias para tais experimentos. Mas, além disso, sugere-se também que haja uma inter-relação das disciplinas: Direção Teatral e Dramaturgia, por exemplo, podem ser disciplinas geradoras de materiais para a experimentação plástica. $\mathrm{O}$ mesmo pode se dar com as disciplinas de Interpretação em relação à prática do figurinista. Enfim, o que se vislumbra aqui - no interior da metodologia tradicional - é que os cursos de teatro sejam mais centrados na prática ou experimentação cênica, envolvendo atividades interdisciplinares. Isto porque Cenografia e Indumentária são disciplinas teórico-práticas que contêm elementos conceituais e elementos referentes à ordem do fazer. Um termo não existe sem o outro, eles se alimentam e se interpenetram, num movimento circular, onde a teoria gera o fazer e o fazer gera a teoria.

Mas, devemos pensar ainda que o licenciado em teatro atuará, em boa parte dos casos, em circuitos alheios a este grande mercado. Devemos pensar também que, por natureza, o gesto criador é sempre transformacional. Ele é agente 
e paciente de uma infinidade de forças. De tal modo que nem sempre as soluções e procedimentos presentes nos livros didáticos são as mais apropriadas, não devendo, portanto, constituírem o único objeto de interesse do arte-educador. É necessário pensar em outros caminhos para a criatividade, caminhos diferentes da "técnica" tradicional e da cultura visual a ela aliada. É necessário ter em vista que as novas tecnologias da imagem e os caminhos da arte contemporânea propõem novas sensibilidades, determinando outras metodologias. De minha parte, tenho experimentado inversões do processo tradicional: gerar a cenografia e o traje não a partir do texto, mas a partir de outras espacialidades (pinturas, fotos, elementos arquitetônicos, entre outros).

Paradoxalmente, o que estes caminhos revelam ao aluno e a nós mesmos é sempre o mesmo: um espaço de visão onde se dá o encontro (neste caso, virtual) do ator e do público, um espaço da metamorfose do ator, do jogo das máscaras, da fusão do real e do irreal. Trata-se nada mais do que formas diferentes de se ver o mesmo fenômeno. 


\section{REFERÊNCIAS}

DIAS, José. A importância da cenografia. O Percevejo, Rio de Janeiro, ano 7, n. 7, p. 11-17, 1999.

DONDIS, Donis A. Sintaxe da linguagem visual. São Paulo: M. Fontes, 2000.

GUÉNOUN, Denis. A exibição das palauras: uma idéia (política) do teatro. Rio de Janeiro: Teatro do Pequeno Gesto, 2003.

HOLT, Michael. Phaidon Theatre manual: costume and make-up. London: Phaidon Press, 1993.

NELMS, Hennig, Scene design: a guide to the stage. New York: Dover Publicatons, 1975.

PARKER, Oren; SMITH, Harvey K. Scene design and stage lighting, New York: Holt, Rinehard and Winston, 1966.

RATTO, Gianni. Antitratado de cenografia. São Paulo: Senac São Paulo, 1999.

SELDEN, Samuel; SELLMAN, Hunton. Stage scenery and lighting: a handbook for non-professionals. New York: Appleton-Centry-Crofts, [19--]. 